Manuel Carmona García

Figura 1. Casa Charles \& Ray Eames, vista del interior. Es un claro ejemplo de un ámbito doméstico conformado por sistemas prefabricados y con acabados industriales, donde los elementos cotidianos toman el control y definen el espacio. Ref. web 1.

Manuel Carmona García.

Arquitecto por la ETSAM. Máster en Análisis, Teoria e Historia de la Arquitectura. Doctorando del Departamento de Composición Arquitectónica de la ETSAM, Universidad Politécnica de Madrid. Actualmente en proceso de prelectura de tesis doctoral.

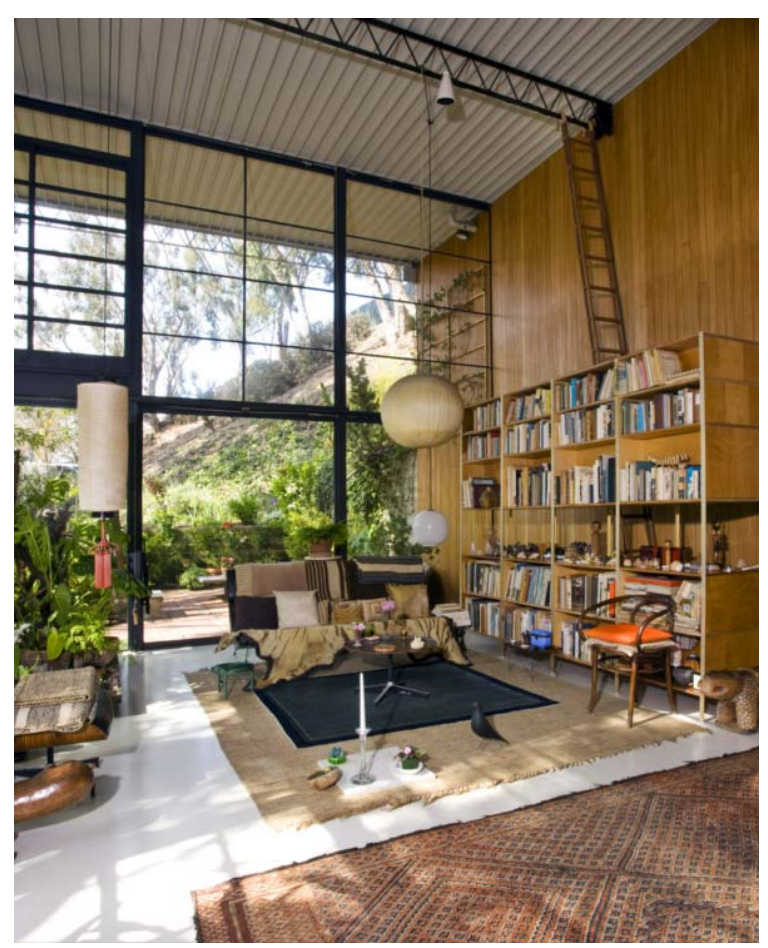

os objetos han jugado un papel imporLtante en la configuración del espacio doméstico contemporáneo. En una sociedad de consumo y de cambios culturales, a partir de la segunda mitad del siglo XX, el objeto se liberaba de su función y adquiría nuevas acepciones, sobre todo por su capacidad comunicativa: el significado comenzaba a prevalecer sobre su uso. La faceta semántica de los objetos permitía, ubicándolos en determinadas zonas, com-

\section{El objeto en el marco de la vida} Sobre el papel del objeto en la configuración del espacio
doméstico contemporáneo

Palabras clave: objetos configuración espacio, espacio doméstico contemporáneo, diseño interior, objetos distribución vivienda, exposiciones mobiliario.

En el marco doméstico contemporáneo, que los nuevos modos de vida reclaman más abierto y más libre, los objetos gracias a su nueva faceta semántica, participan en la organización y cualificación del espacio. En dicho proceso de configuración los elementos actúan, por un lado distribuyendo y ordenando, organizados en sistemas basados en relaciones topológicas y geométricas, y por otro añadiendo una nueva dimensión psicológica a los nuevos ámbitos, permaneciendo como elementos simbólicos o actuando como mecanismos que influyen en la vivencia y en la percepción espacial. En este artículo se realiza un acercamiento a la visión del objeto en el marco contemporáneo, siguiendo los estudios sociológicos de Baudrillard, Moles o Barthes, entre otros, y a través de las exposiciones y ferias de mobiliario y enseres para el hogar que proliferan, en una sociedad de consumo, a partir de los 60. Así mismo se establece un sistema de análisis que determina una correspondencia entre características y cualidades que son propias del espacio doméstico contemporáneo y los modos de actuación de los objetos en dichos entornos, constatando, de esta manera, que los objetos contribuyen a configurar ámbitos con unas determinadas propiedades gracias a sus modos de relación y conexión en el espacio.

binándolos y relacionándolos entre sí, crear un discurso que estructuraba el espacio. De esta manera se establecía un nuevo lenguaje.

Los nuevos entornos domésticos, a su vez, respondian a la necesidad de espacios más amplios y polivalentes, adaptándose a los nuevos modos de vida. Los objetos, en ese nuevo contexto, ritmaban el espacio en base al discurso elaborado con ese nuevo lenguaje que surgía de su capacidad organizativa y comunicativa. Se establecía así una correspondencia entre todo lo que se expresaba con aquella combinatoria ilimitada de objetos -dispuestos en el espacioy las características y cualidades de los entornos, que eran propias de un nuevo marco doméstico contemporáneo.

Los nuevos paradigmas, que giraban en torno a un nuevo espacio doméstico, dirigían a cuestiones sobre "¿cómo se convierte una casa en un hogar en una época tan desarraigada como la nuestra?" (NorbergSchulz 2005: 97). En aquellos años algunos arquitectos habian puesto ya en marcha varias interpretaciones de la planta libre, pero la vida en el espacio abierto seguía siendo un mero hecho físico si no se le confería algún significado, una vivienda implicaba algo más que un cobijo.

La sociedad industrial había provocado un cambio radical en el hábitat del hombre, y había creado un nuevo espacio cuyo rasgo más peculiar residia en la proliferación de objetos manufacturados. En ese mundo de 


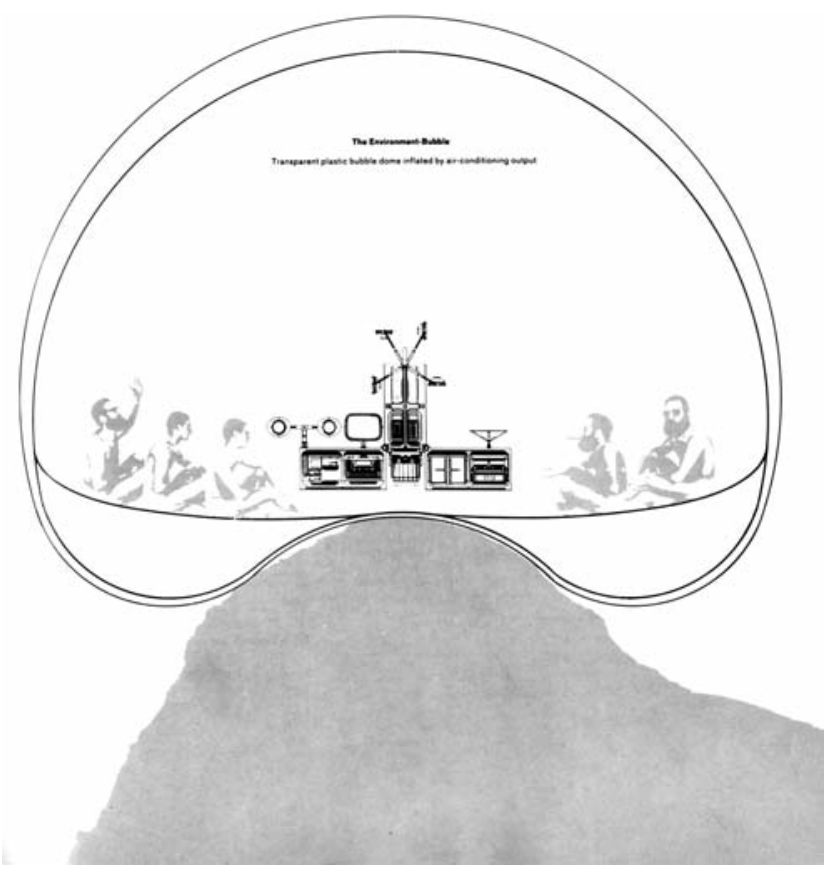

Figura 2. 'The Environment-Bubble'. La ilustración: François Dallegret representaba al hombre bajo una cápsula de plástico. La burbuja se inflaba con el aire caliente que emitía un kit de equipamientos transportable llamado standard for living, una idea heredada de Buckminster Fuller, y que podia colocarse en cualquier lugar. El kit prompesto por Banham agrupaba en un solo elemento a todo el equipamiento necesario para la vida diaria: desde la placa de fuegos, situada en el centro del bloque, hasta el equipo de música, o la máquina de fabricar cubitos de hielo. (Banham 1965: 77). consumo, arquitectos, sociólogos, psicólogos, etc., ponían especial atención en indagar sobre el concepto moderno de objeto y su incidencia en los hogares. Así, a partir de los años sesenta, huyendo de las definiciones más tradicionales, emergía una nueva visión que se apoyaba en la idea de objeto como elemento social y comunicativo, desviándose de consideraciones meramente funcionales e incidiendo en el significado. En este contexto primaba su interpretación como signo y su capacidad de crear un discurso en relación con otros objetos, constituyendo sistemas o conjuntos.

\section{Una nueva visión del objeto}

Según los estudios de Abraham A. Moles (1975) habia un mensaje semántico, que se basaba en el lenguaje de los objetos reunidos en un interior. Simplemente la acción de ocupar el espacio podía convertirse en el medio para la creación de un discurso, y a través de dicho mensaje se cargaba de significado al espacio. Algo que Jean Baudrillard también atribuía a los objetos: "sin relación no hay espacio, pues el espacio no existe sino abierto, suscitado, ritmado, ampliado por una correlación de objetos y un rebasamiento de su función en esta nueva estructura. El espacio es, de alguna manera, la libertad real del objeto" (Baudrillard 1969:17), pero constituidos especialmente en grupos o sistemas de relaciones normalizados. El afianzamiento de la planta libre en la vivienda y la nueva visión del objeto como elemento social y como signo, propiciaban un proceso de configuración del marco contemporáneo, que estaba basado en sistemas de relacio- nes y conexiones de elementos en el interior del mismo.

Los nuevos modos de vida hacían de la casa un lugar cada vez menos para habitar durante generaciones y más un sitio en el que las familias pasaban sólo una parte de la vida para trasladarse a otro lugar. Además determinadas funciones ya no precisaban un espacio específico, como separar el comedor de la sala de estar, o incluso la cocina, por lo que se requerian entornos más unificados y polivalentes que sirvieran para una mayor variedad de actividades distintas a la vez. Las nuevas soluciones constructivas permitian optar a ámbitos con luces mayores y con amplias superficies acristaladas, lo cual ofrecía así mismo mayor libertad espacial, como ocurría en la Glass House de Philip Johnson o en la casa Farnsworth de Mies van der Rohe. Y en otros casos los interiores dejaban vistos los propios elementos constructivos de aspecto industrial e incluso las instalaciones, como en la casa de Charles y Ray Eames. Para sus casas, los Eames utilizaban la tecnología para proporcionar un recinto que tuviera lo esencial para satisfacer una vida confortable y el ocupante después podía transformar esa estructura estableciendo su propio discurso, llenándola de accesorios de su propia vida.

La mejora en los sistemas de calefacción también hizo menos importante la necesidad de habitaciones diferenciadas. Los avances técnicos ya permitian mantener acondicionada cualquier parte de la casa y durante más tiempo. Tales eran las esperanzas puestas en el progreso de los servicios mecánicos para edificios y en las técnicas derivadas de la investigación aeroespacial que algunos críticos, como Reyner Banham anunciaban que con un paquete compacto de elementos técnicos, totalmente agrupados, que emitiera aire caliente sobre el suelo y que contuviera todo el equipamiento necesario para proporcionar al usuario una vida confortable, era más que suficiente. Bajo el lema 'un hogar no es una casa' descartaba que la presencia de una casa fuera necesaria para que existiera un hogar. Siempre que se tuvieran las necesidades cubiertas, y que existiese un cierto grado de confortabilidad y climatización, era suficiente. Los muros y la cubierta que definian el espacio doméstico ya no eran necesarios, según sus argumentos, con los sistemas de acondicionamiento y los equipamientos en buen servicio todo estaba resuelto, "la casa era poco más que un núcleo de servicios en un espacio infinito" (Banham 1965: 76). 


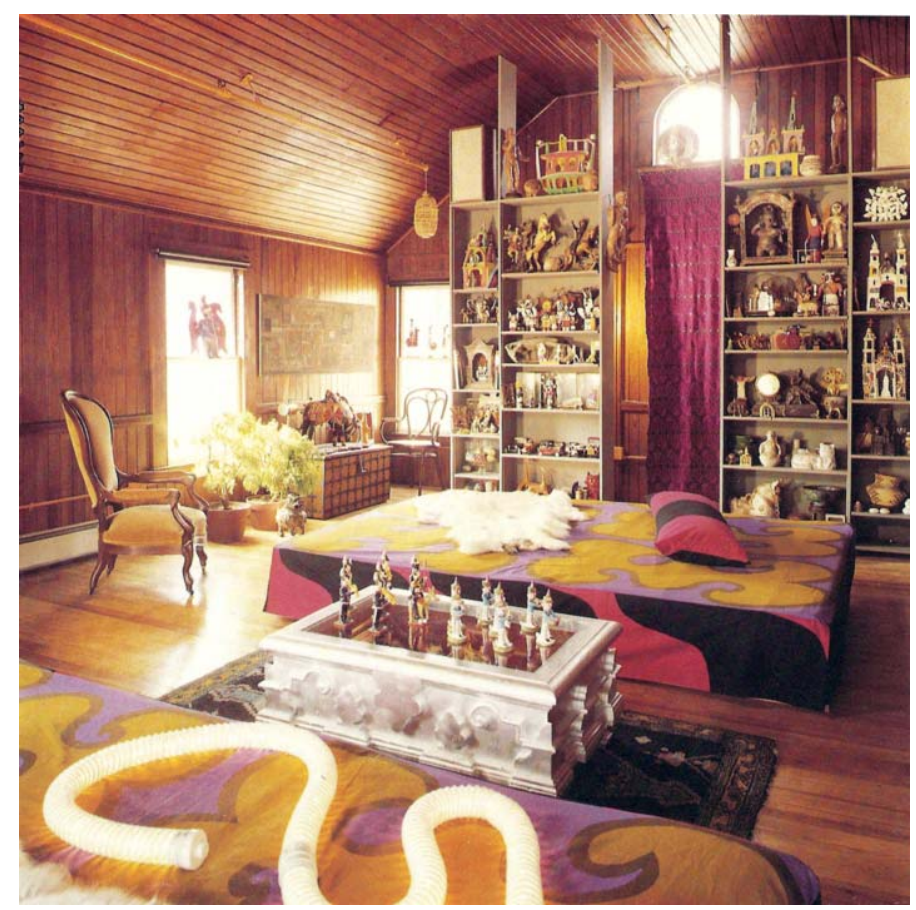

Figura 3. Casa Moore en Essex, Connecticut, por Charles Moore Ass. en 1973. Vista del interior del espacio estar-dormitorio. Cuando Charles Moore trasladó su oficina y su casa a Essex, Connecticut, aprovechó la ocasión para recuperar una de sus aficiones: coleccionar y desplegar su colección con profusión. Alli se exhibian libros, santos mexicanos, soldaditos de juguete, relojes divertidos, jaulas de pájaro, pieles de lobo y una elegante lámpara italiana encendida que serpenteaba sobre la cama. (Allen 1980: 74)

Página siguiente. Arriba. Figura 4. 'La Casa del Futuro', una propuesta de Alison \& Peter Smithson presentada en la Daily Mail Ideal Home Exhibition, en 1956, que representa cómo seria una vivienda veinticinco años después de la fecha de la exposición. (Vidotto 1997).
El desarrollo de la planta abierta demostraba no sólo una preocupación por una configuración novedosa, sino por el problema de cómo acomodar las máquinas, donde la casa se convertía en un marco para el equipamiento (Moore, Allen, Lyndon 1999: 79). En una planta libre de tabiques, los propios muebles y demás aparatos domésticos eran los que se encargaban de zonificar y definir las áreas basándose en las tareas y las actividades diarias. Los objetos, acoplándose en contenedores cada vez más neutros y diáfanos, adquirian nuevas acepciones para cumplir su papel dentro de la organización espacial. El hogar, cada vez más diáfano, precisaba de sistemas que ordenaran y distribuyeran dependiendo de las necesidades y de las actividades que allí se desarrollaban. En este sentido, los objetos -los muebles, las máquinas, los equipamientos-, a medida que ocupaban el espacio, contribuian a configurar lugares que respondian a algo que ya venía demandando el habitante contemporáneo: mayor libertad espacial y versatilidad.

"El nuevo tipo de habitante es un informador activo del ambiente. Dispone del espacio como de una estructura de distribución; a través del control de este espacio, dispone de todas las posibilidades de relaciones reciprocas y por lo tanto, de la totalidad de los papeles que pueden desempeñar los objetos", decía Jean Baudrillard (1969: 26). Los objetos, organizados mayormente en grupos o sistemas, en base a sus relaciones, constituian un discurso cuya finalidad era estructurar y dar senti- do al espacio en cuanto a organización y orden. Una vez organizado el espacio, surgian otro tipo de discursos, más bien subjetivos, orientados al tratamiento del entorno, y que estaban constituidos por otros sistemas de objetos añadidos, los cuales otorgaban nuevas dimensiones al espacio gracias a las connotaciones asociadas a los mismos y a su influencia psicológica en la percepción y en la vivencia.

El 'aditamento', denominado así por Charles Moore en La casa: forma y diseño, consistía en la posibilidad de 'añadir algo' a la casa: "al rodearte de cosas que tienen un significado especial para ti, las cuales has escogido entre otras muchas similares, puedes añadir una nueva dimensión al lugar que habitas y aumentas su capacidad para nutrir tu imaginación" (Moore, Allen y Lyndon 1999: 214). En dicho acto el ocupante utilizaba objetos, los emplazamientos de éstos, así como colores, texturas y materiales, para establecer un medio que pudiera reconocerse como suyo. Algo que Moore aplicó en muchas de sus viviendas, como en su casa de Essex, Connecticut, para así entenderlas como su propio hogar. En este proceso se establecían conexiones psicológicas asociadas a los objetos personales y a los rituales que se producian por su propia disposición, utilizados como focos o hitos. Los aspectos simbólicos y los factores asociados al tratamiento del espacio empezaban a formar parte, de forma sistematizada, de lo que Baudrillard llamaba 'estructura de ambiente'.

\section{El espacio doméstico a través de los objetos en las exposiciones}

Roland Barthes (2009) decía que una de las mejores maneras de comprender esta labor del objeto era observándolo en su estado más enfático e intencional. Se refería a cuando se utilizaba para configurar escenografias de teatro, de cine o en la publicidad. Las muestras eran una parte importante de la cadena publicitaria y, teniendo en cuenta además la creciente cultura de consumo y el florecimiento de grandes productoras de mobiliario y enseres para la casa, muchas de ellas a partir de los años sesenta se consolidaron a nivel internacional, como las ferias de mueble de que se venían celebrando en ciudades como Colonia o Milán. La propia promoción de los objetos, en muchos casos, llevaba a una demostración pública de cómo había que utilizarlos y cuál era el contexto ideal para ubicarlos. Para ello se recreaban ambientes que aparecian como si surgieran de la interacción entre el usuario y los objetos, y además representaban los hoga- 


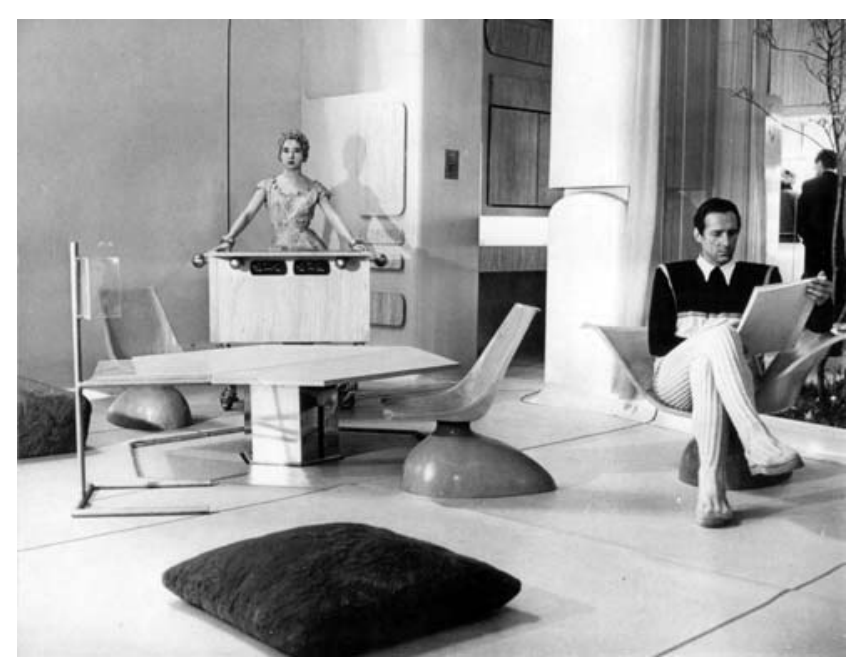

res perfectos para albergar a aquellos nuevos modos de vida que en ellos se interpretaban. Estas recreaciones de ambientes se convirtieron en auténticos laboratorios de ideas donde arquitectos y diseñadores, desde los Smithson hasta Rem Koolhaas, a lo largo de varias décadas, aprovecharon para reflexionar sobre el concepto de hogar, expresando sus ideas en dichas exposiciones como si de escenógrafos se trataran.

Palestra', presentada por Rem Koolhaas en la XVII Triennale de Milán, en 1986, representando, de forma crítica, el hábitat del sujeto hedonista contemporáneo. Ref. web 2.

Figura 6. Imagen de visitantes en la exposicion 'Italy: the New Domestic Landscape' celebrada en el MoMA, Nueva York, 1972. La muestra supuso un gran éxito de público, siendo la más visitada en la historia del museo hasta el momento. Fotógrafo: Leonardo LeGrand. Ref. web 3.
El interés mostrado incluso por los museos para participar en estas exposiciones, avalaban lo que en ellas se producía. El MoMA de Nueva York acogió algunas de las más relevantes, como las incluidas en el programa 'Good Design', celebrado desde 1950 a 1953 -, en colaboración con el centro comercial Merchandise Mart de Chicago, o la exposición 'Italy: The New Domestic Landscape' de 1972, que tuvo gran repercusión a nivel mundial. Las representaciones de ambientes domésticos, que allí se producian, a veces contaban incluso con actores que mostraban cómo sería el día a día en aquellos hogares ideales, en los que objetos de nueva generación y equipamientos sofisticados hacian ver que la vida de sus visitantes podía ser más cómoda y confortable.
En aquellas muestras, todo consistia en expresar ideas colocando objetos de una manera u otra, relacionándolos dentro de los ámbitos de los que se disponía, ya que cuando se trataba de acomodar elementos, en realidad se hablaba de relaciones. Incluso Norberg-Schulz decía que las relaciones entre elementos solían ser más importantes que los propios elementos (Norberg-Schulz 1998: 90), por lo que la palabra 'relación' iba implícita en el hecho de distribuir objetos. De forma similar, a lo que ocurría en las muestras, este hecho relacionaba la forma de constituirse los sistemas de objetos con las características de los ámbitos.

\section{El papel del objeto como elemento orde- nador}

Los entornos domésticos contemporáneos, básicamente requerian de las relaciones de elementos más elementales, es decir, de las topológicas -proximidad, densidad, accesibilidad, etc.- con el fin de que los objetos distribuyeran y ordenaran según las actividades y usos que se producían. Por ejemplo, todo mueble requería ser accesible sin esfuerzo, y este simple hecho normalmente marcaba las distancias y posiciones de unos objetos frente a otros. Los objetos más próximos tendian a crear grupos, lo que establecía visualmente diferentes zonas dentro de un mismo ámbito, o incluso una mayor o menor concentración de objetos podia significar diferentes cosas dentro de un mismo espacio. Sin embargo, existian otros tipos de relaciones. A. Moles enunciaba en 1972 que todo objeto irradiaba a su alrededor, y que el efecto de dicha influencia generaba jerarquías, ya que su propio dominio exigia que no existieran objetos de su mismo tamaño en sus inmediaciones. De esta manera, un elemento centrado en el espacio, simplemente por su influencia psicológica, procuraba orden a su alrededor. Varios son los ejemplos y diferentes los tipos de elementos centradores.
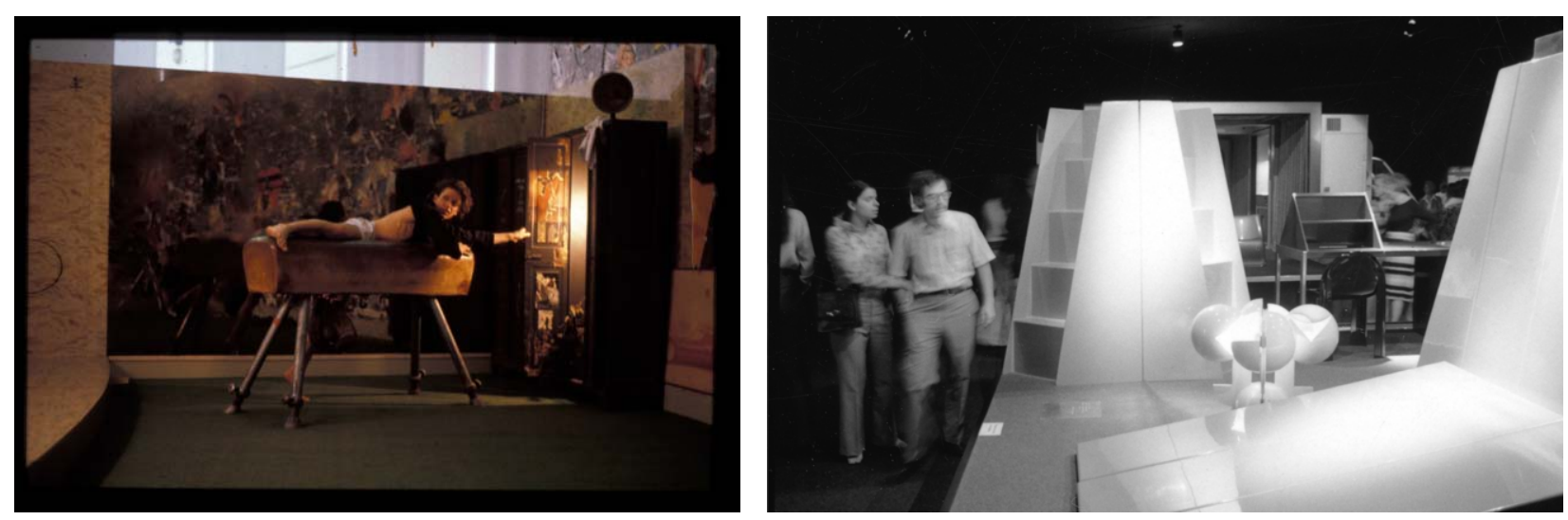

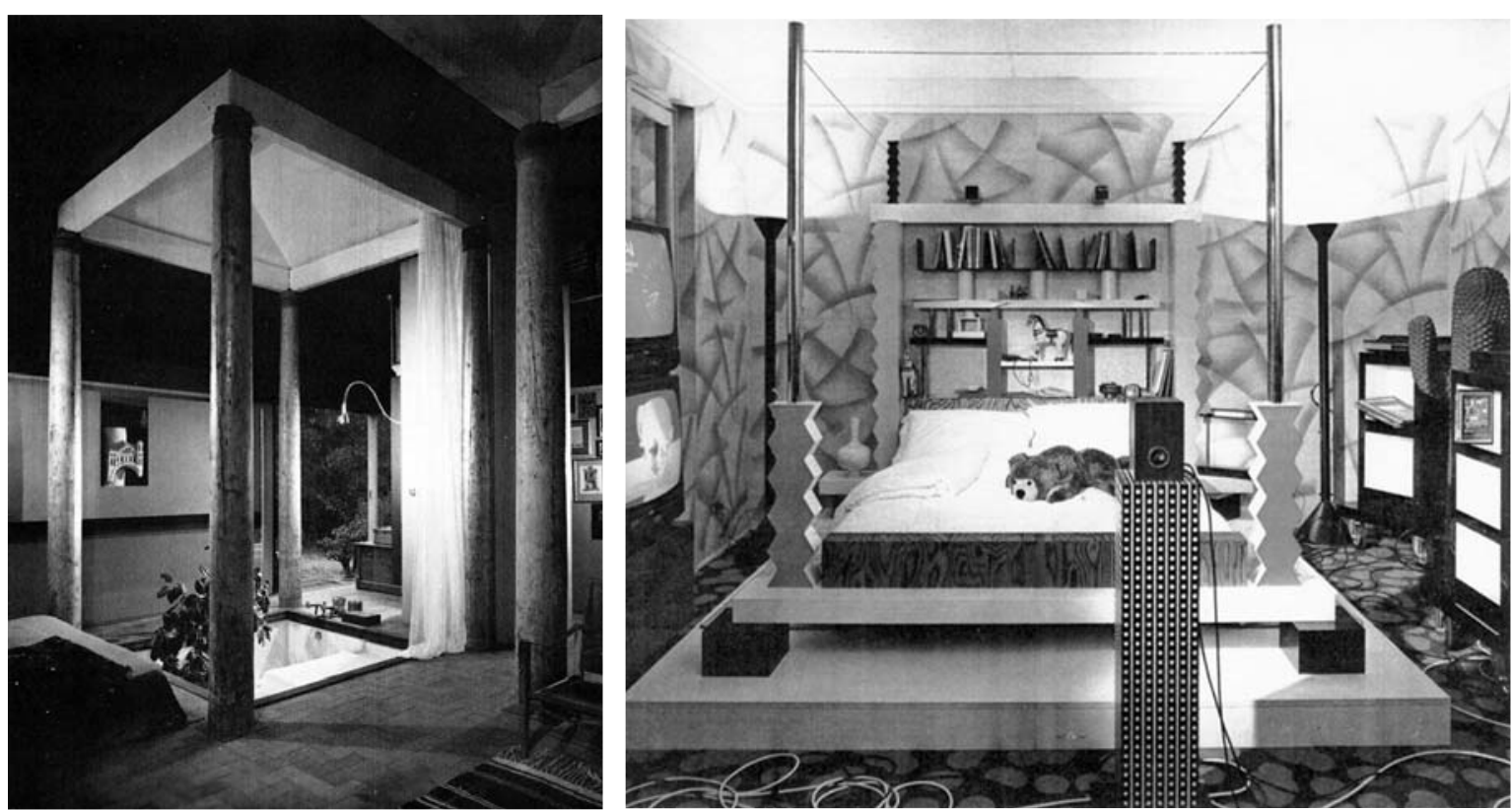

Figura 7. Casa Moore en Orinda, California. Charles W. Moore, 1962. Imagen de uno de los dos ediculos que organizaban la planta, libre y abierta al paisaje por sus cuatro esquinas. Fotógrafo: (c) Morley Baer. (Johnson 1986: 101)

Figura 8. Letto XVII, por Ettore Sottsass. La cama configuraba un espacio por sí misma, pero a su vez también conformaba un ámbito a su alrededor como efecto de su propia área de influencia. Foto: (c) Ettore Sottsass. Ref. web 4.

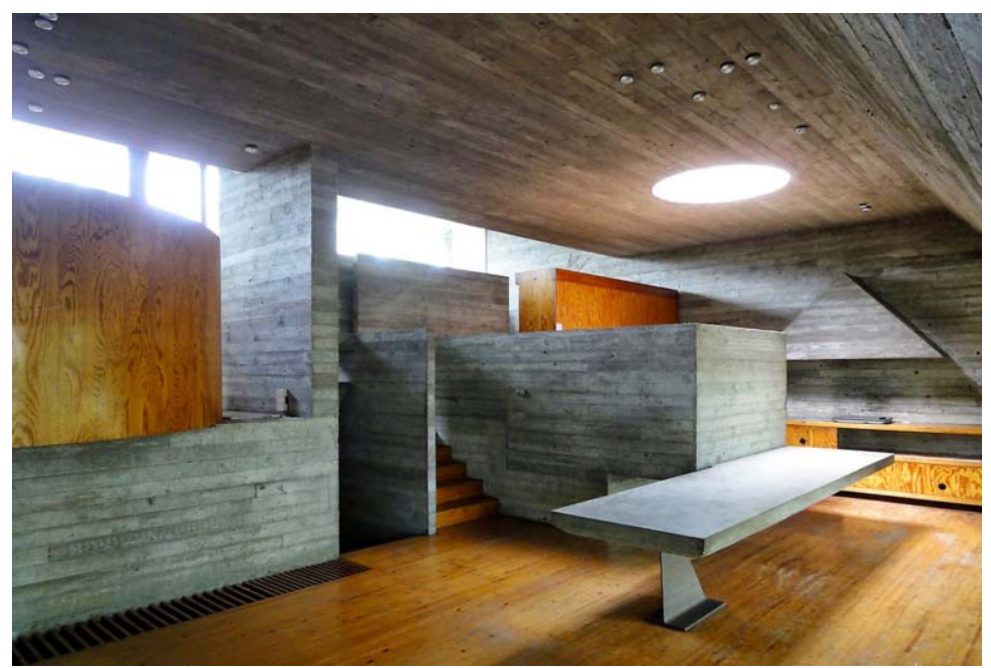

A veces estos elementos, por su propia configuración formal, podian representar espacios por sí mismos dentro del propio ámbito de la casa. Entonces se producían dos fenómenos a la vez, por un lado un efecto de orden y jerarquía a su alrededor, por su área de influencia, y por otro lado por un efecto contrario, hacia el interior de dicho elemento, se generaba un segundo nivel de interior, adquiriendo la cualidad de lugar especial, de 'centro del universo' dentro de la casa. Es lo que se podía llamar 'la casa dentro de la casa', lo cual tuvo especial aplicación en los espacios domésticos de los sesenta y los setenta. En realidad esta idea era tan moderna como tradicional, sin embargo, su contemporaneidad radicaba en la interpretación que se hizo de los antiguos ediculos de los que hablaba John Summerson en Heavenly Mansions en 1949 -lugares sagrados dentro de las iglesias o templos, o en las villas neoclásicas inglesas-, que se incorporaban dentro del hogar para conseguir una imagen poética.

Existian diferentes razones que llevaban a la representación formal de la intimidad, pero quizá la más interesante era la idea de transformar el hábitat introduciendo lo simbólico y lo psicológico del mundo interior en el ámbito doméstico. La creación de nuevos niveles de interior en la casa significaba huir de la realidad, ofrecer la posibilidad de evadirse. Basándose en la filosofia de Gastón Bachelard, Charles Moore recurrió en su casa en Orinda, California (figura 7) como en otras tantas, al elemento centrador con forma de edículo. Formado por cuatro pilares y una cubierta, dentro del mismo espacio, además de generar recorridos a su alrededor y regularizar la percepción del espacio gracias a su área de influencia, también establecía aquellos distintos niveles de interior que tanto influían en la vivencia de la casa. En estos casos, donde prevalecía la planta abierta, era necesario contar con ciertos 'lugares' de confinamiento para proporcionar los grados de intimidad necesarios para configurar un espacio doméstico abierto, pero con cierto grado de privacidad a la vez.

Algunos muebles, especialmente las camas, también podian convertirse en auténticos reductos de confinamiento. Establecian lugares interiores dentro de la habitación y disponían, gracias a su efecto de irradiación, de todo un sistema de objetos a su alrededor que constituian sus propios dominios, como ejemplo, el espacio Letto XVII presentado por Ettore Sottsass en la Triennale de Milán en 1986. 
Página anterior. Abajo. Figura 9. Casa van Wassenhove en Sint-Martens-Latem, Bélgica. Juliaan Lampens, 1974. Vista interior de la vivienda. Ref. web 5.

Figura 10. Vista del estudio Lou Dazinger en Hollywood, California. Frank $O$. Gehry, 1964. (Friedman 2009: 115)

Figura 11. Casa Alexander en Montecito, California. Roland Coate, 1971. Vista del espacio principal de la casa. Ref. web 6.

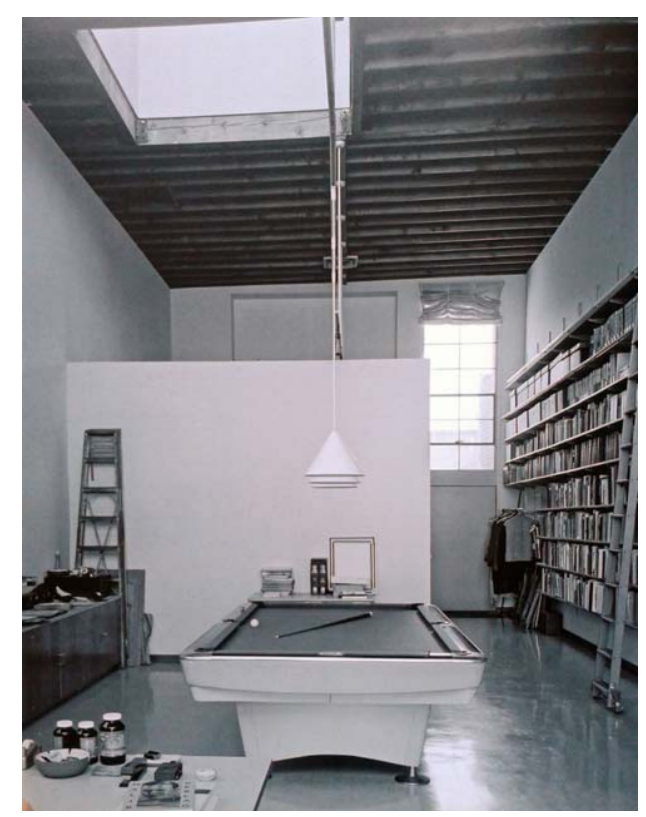

Dentro del espacio los objetos centradores también podian actuar como elementos articuladores de la planta. Por contraste, y por aproximación, como en la casa Wassenhove de Juliaan Lampens en Latem, donde el diálogo que se producía entre dos elementos, uno de hormigón y otro de madera, involucraba en sus relaciones, a los espacios intermedios y a las zonas periféricas, y multiplicaba las posibilidades espaciales. A su vez, por su efecto centrador, unificaban los distintos niveles existentes en un solo ámbito.

El efecto psicológico de irradiación de un objeto con características formales o connotaciones fuertes, e incluso contradictorias, podía llegar a desplazar al resto de los muebles hasta los limites del entorno fisico. Como es el caso de la mesa de billar ubicada en el centro del estudio del diseñador gráfico Lou Danziger, proyectado por Frank O. Gehry. Este elemento, a pesar de apropiarse de un lugar de trabajo -al que no pertenecía funcionalmentedesplazaba todo el mobiliario al perimetro del ámbito, y consiguía configurar un espacio perfectamente distribuido y ordenado.

También la ambigüedad espacial, propia de muchos ámbitos domésticos contemporáneos -por los sistemas constructivos empleados o por la falta de tabiquería, entre otras razones-, precisaba que los objetos distribuidos, según relaciones de accesibilidad, zonificaran y estructuraran la planta. Por proximidad o similitud, sus relaciones también cualificaban los entornos a medida que se iban acoplando y agrupando a lo largo del tiempo según las necesidades. Ejemplos claros eran la casa Kappe diseñada por el propio arquitecto Raymond Kappe en 1965 en California o la casa Alexander diseñada por Roland Coate en 1971 figura 11), en los que los propios elementos, diferenciados del fondo espacial, tomaban las riendas distributivas y compositivas en espacios especialmente abiertos y diáfanos.

\section{Los muebles transformables y el espacio flexible}

Generalmente los espacios, eran cada vez más abiertos pero también de menores dimensiones, por lo que debían ser ámbitos fácilmente adaptables a las circunstancias de cada momento. Las nuevas necesidades reclamaban lugares polivalentes y mutantes, donde la flexibilidad fuera la principal característica. En este aspecto, la técnica tenía mucho que ofrecer. Las posibilidades que procuraban los nuevos materiales y sistemas de montaje facilitaban el desarrollo y la producción de muebles transformables, que en muchos casos

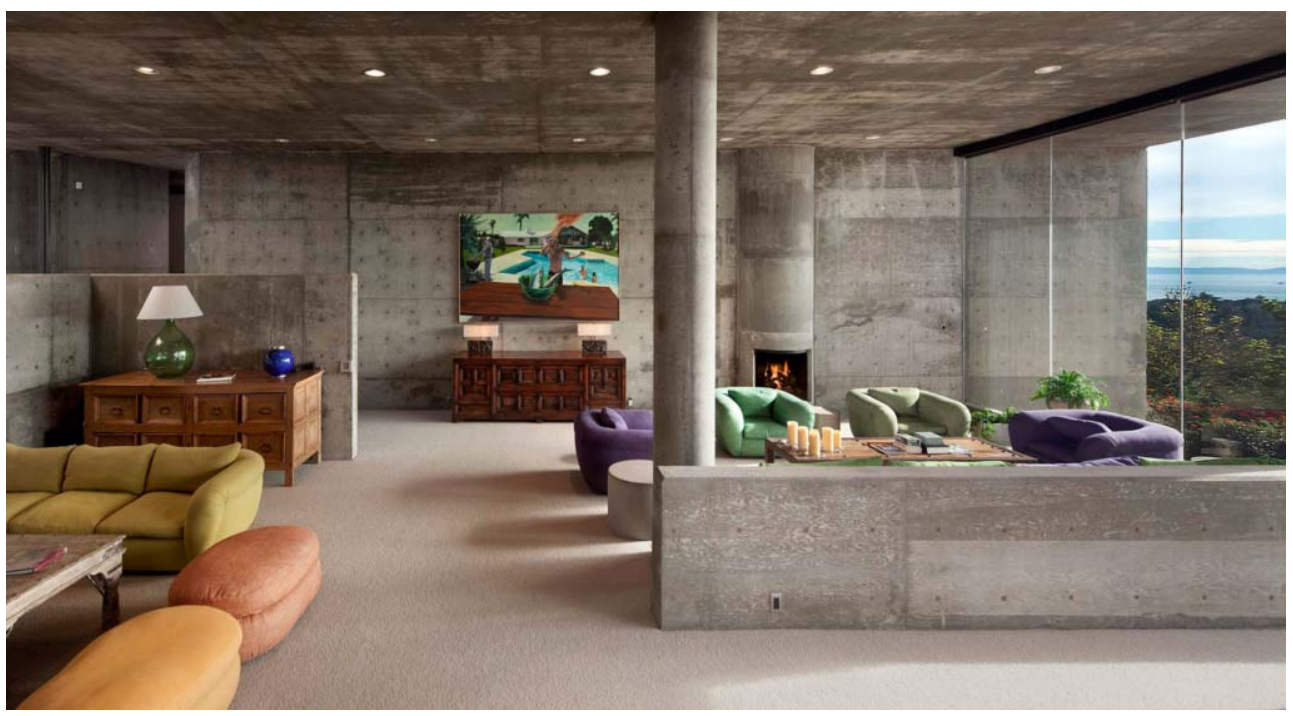




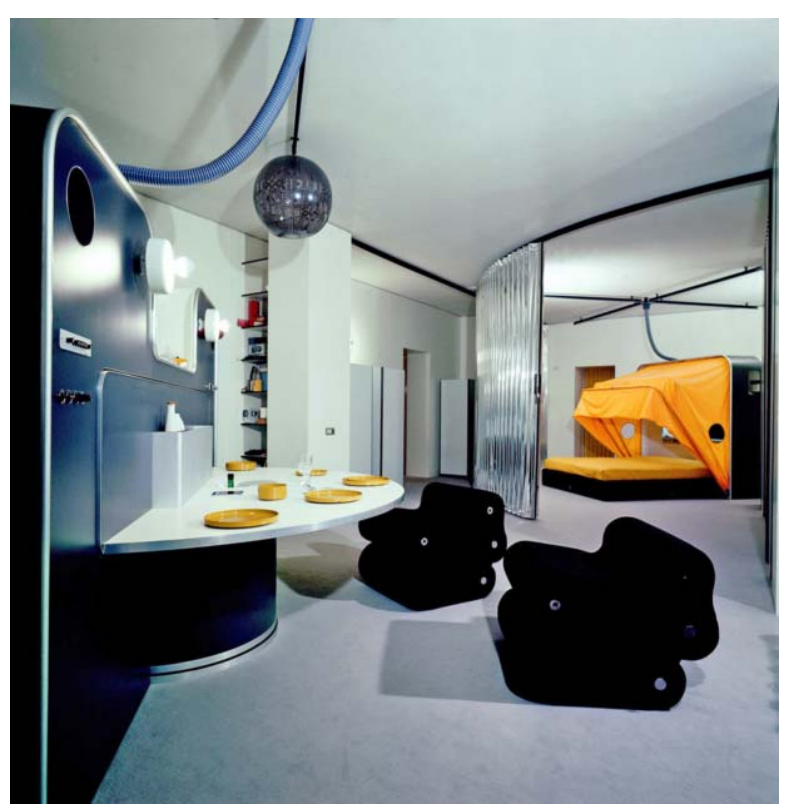

Figura 12.

Apartamento en vía Argelati, 30b, Milán. Joe Colombo, 1971. Las múltiples opciones espaciales se generaban gracias a la movilidad de dos muebles principales colocados en cada extremo de la casa: 'Roto-living', en primer plano, $y$ 'Cabriolet-Bed' al fondo. Ref. web 7.

Figura 13. Planta general donde se aprecia el sistema de equipamiento móvil propuesto por Ábalos $y$ Herreros en el concurso Housing \& City, en 1989. Ref. web 8. 'transformaban' el concepto de casa. A finales de los cincuenta hubo un acercamiento importante a este tipo de hábitat a través de la 'Casa del Futuro' (figura 4), una propuesta presentada por los Smithson en 1956 en la Daily Mail Ideal Home Exhibition, en la que todos los muebles tenían formas ergonómicas. Gran parte del equipamiento y del mobiliario se podía encastrar en el suelo, y los armarios y electrodomésticos, incluso la bañera, parecian haber tomado su forma generada por el movimiento del cuerpo. Otras propuestas similares, en años posteriores, tomaron como referencia la de los Smithson. Por ejemplo, inspirados en esta casa, el grupo Archigram presentaba en 1967 'Living 1990', otra casa del futuro, promovida por el Weekend Telegraph Magazine, en la que a través del uso de

robots, se ofrecian todas las posibilidades para las actividades diarias y en la que todo era movible y ajustable, hasta los cerramientos.

En este tipo de hábitats, había dos maneras de abordar la flexibilidad. Por un lado podia basarse en la movilidad de un sistema de muebles transformables, dentro de un espacio con los limites definidos e inamovibles. Y por otro lado había casos cuya flexibilidad se apoyaba en la movilidad de elementos más bien arquitectónicos -tabiques, mamparas-, lo que hacia que el contenedor fuese lo que realmente mutaba. El mejor exponente de esta primera forma de entender la movilidad en el espacio doméstico fue Joe Colombo, que decia: "para adaptar el hogar a los nuevos modos de vida, aunque el contenedor sea fisicamente un espacio estático, el contenido debe ser dinámico" (Kries y von Vegesack 2005:41). Siguiendo este principio, que otorgaba exclusivamente a los objetos la facultad de caracterizar a un espacio como flexible, reformaba su propio apartamento en Milán (figura 12). Dentro de un espacio único, Colombo incluía una vivienda para él y su esposa, y también su estudio. La capacidad de transformación formal y la polivalencia de dos grandes muebles-bloque, que diseñó y colocó estratégicamente en un entorno diáfano, eran la base del proyecto.

Cada mueble representaba, las actividades de día - 'Roto-living'- y las de noche -'Cabriolet-Bed'-, y al estar dispuestos cada uno en un extremo del espacio, abarcaban la configuración de todo el ámbito, ejerciendo el control de sus dominios. La relación entre ambos muebles en constante cambio, contribuía a caracterizar un espacio que mutaba para adaptarse a las actividades que se producian a lo largo del tiempo. En las intersecciones de las áreas de influencia de los bloques discurrian diferentes series de pequeños artefactos, también transformables, que matizaban las cualidades del lugar y se iban disponiendo en función de las necesidades.

El concepto de movilidad de los artefactos domésticos fue evolucionando a lo largo de los años, y este cambio se aprecia claramente si se compara el proyecto anterior con la propuesta de viviendas que realizaron Ábalos y Herreros para el concurso 'Housing \& 

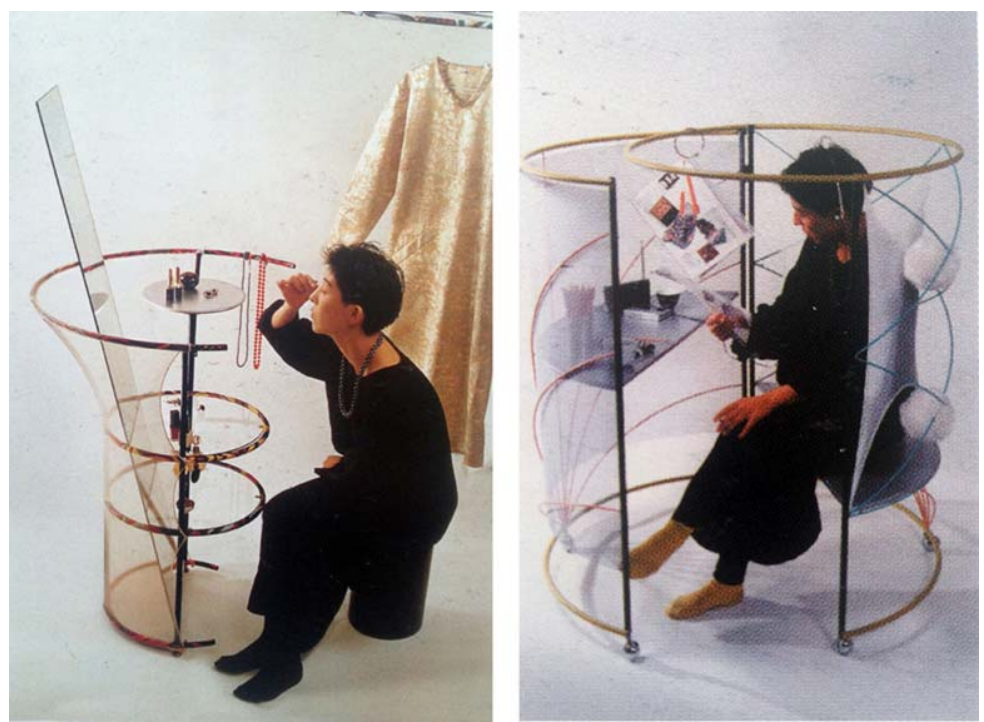

Figura 14. Mobiliario del Pao de la muchacha nómada de Tokio, propuesto por Toyo Ito, en 1985. Ref. web 9.

City' en 1989. Como en el proyecto de Colombo, la forma del espacio estaba limitada por los cerramientos, así que lo que se afrontaba de nuevo era una flexibilidad basada en la capacidad de transformación del equipamiento. Las opciones de movilidad de servicios y mobiliario configuraban un espacio cuya característica de base, era la flexibilidad. Pero en este caso, cuando hablaban de movilidad ya no significaba polivalencia, ni se contaba con grandes artefactos, ni con robots, sino con ligeros objetos que se caracterizaban por su la fragilidad y liviandad.

La flexibilidad, a finales de los ochenta, se reflejaba en pequeños objetos manejables y ligeros, que habian asumido la obsolescencia y el reciclaje de la cultura del 'usar y tirar' como parte de su movilidad, de la misma manera que el escaso mobiliario que ocupaba los 'Pao' de la muchacha nómada de Tokio de Toyo Ito -Pao-1: 1985, Pao-2: 1989- basaban su movilidad en su transportabilidad gracias a su ligereza y casi transparencia.

La asimilación de sofás-cama, de camas plegables, etc., dirigía a otro tipo de flexibilidad, que iba asociado a la capacidad de movimiento de los elementos constructivos

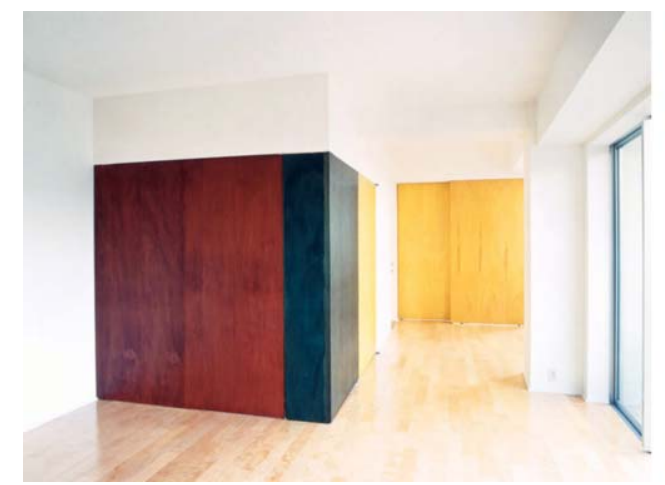

que delimitaban geométricamente el espacio. Se basaba en la movilidad de tabiques correderos, de muros pivotantes, en pavimentos que podian elevarse, etc. Perceptibles y diferenciados, el movimiento de estos elementos generaba un sistema de relaciones espaciales cambiantes que dotaban de mutabilidad y flexibilidad al marco doméstico. El desplazamiento cómodo y rápido de tabiques móviles permitía por ejemplo que las habitaciones pudieran hacerse mayores o subdividirse. Lo interesante era que estas operaciones podían realizarse rápidamente varias veces al día y nunca eran irreversibles. En 1989 Steven Holl realizaba en Fukuoka un bloque de apartamentos en los que, el espacio disponible podía cambiar de forma significativa por las combinaciones posibles gracias al movimiento de tabiques y paneles. Estos elementos, en un proceso de 'objetualización' eran mayormente perceptibles y diferenciables gracias al tratamiento cromático al que habian sido sometidos y que los distinguía de los demás. En ese aspecto se multiplicaban visualmente las variaciones compositivas que se producian en base a una combinatoria de relaciones de llenos y vacíos y de división y unificación, al mismo tiempo.

\section{La apropiación como nuevo modo de vida}

Pero los ámbitos contemporáneos, además de caracterizarse por su flexibilidad también se definian por su capacidad para albergar tipos de vida alternativos. Los movimientos contraculturales de los sesenta que surgian de corrientes como el movimiento hippie, la generación beat americana, el espiritu de mayo del 68, las críticas a los esquemas de la familia tradicional, etc., encontraban sus caracteres más distintivos en el antiautoritarismo, la originalidad, la creatividad, la espontaneidad o la vida en comuna. En este contexto, un grupo de artistas afincados en el SoHo de Nueva York, inventaron un nuevo concepto de espacio doméstico que ligaba inseparablemente un tipo de ámbito, más

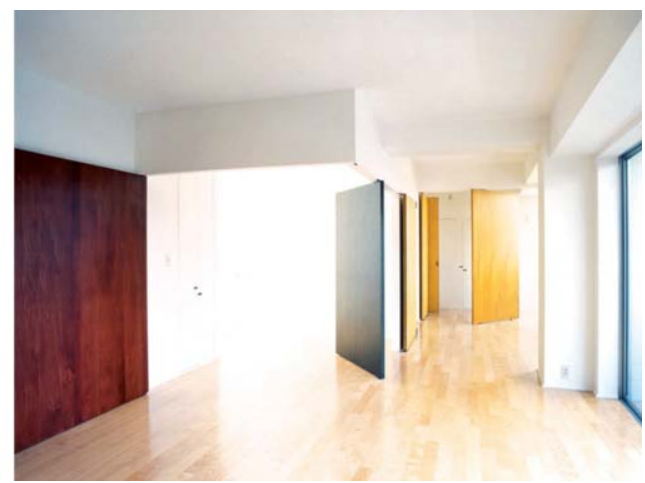

Figura 15.

Apartamentos en Fukuoka, Japón. Steven Holl, 1989. Vista interior de un apartamento en el que se aprecia la mutabilidad del espacio gracias a la posibilidad de combinaciones de tabiquería móvil, puertas y armarios. Ref. web 10 


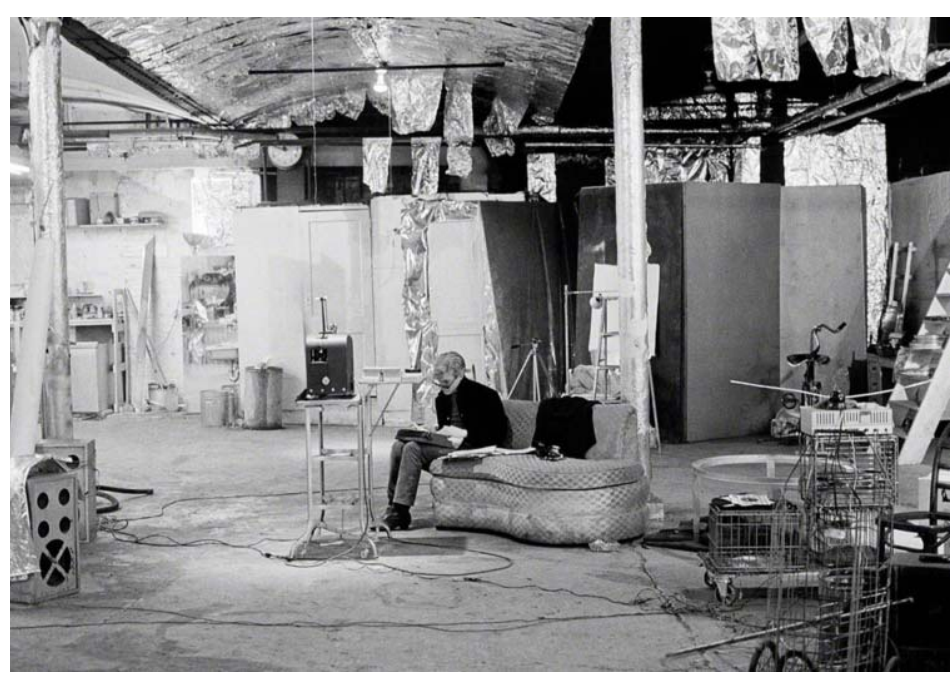

Figura 16. The Factory, por Andy Warhol en un antiguo almacén entre la calle 47 y la tercera Avenida de Nueva York en 1965. Fotógrafo: Nat Finkelstein. Ref. web 11.

Figura 17. Diagoon Houses, Delft. Herman Hertzberger, 1970. Vista interior de una de las viviendas. (Hertzberger 1991: 66)

Figura 18. Indiana Project. Venice, California. Frank $O$. Gehry, 1981. (Gehry 1988: 115) bien inédito, con un nuevo modo de habitar. Para ello, aprovecharon antiguos almacenes en desuso, los convirtieron en viviendas -lo que, en general, se conoce como el loft- y asociaron un modo de vida más libre y artística a un nuevo sistema de apropiación del espacio, en un proceso invasivo de objetos. La versión de este fenómeno más conocida fue The Factory, un espacio promovido por Andy Warhol en 1965, que reflejaba tanto los aspectos progresistas de la vida comunal como el ambiente underground de los sesenta.

Aparentemente caótica y basada en una ocupación despreocupada con objetos reciclados y descontextualizados, la apropiación surgía como un acto existencial y creativo a la vez. Para ello recurría a lugares cuyas características -diáfanos, de aspecto industrial, o reconvertidos- propiciaban ese modo de vida. De esa manera también surgian espacios creados ex profeso, con el fin de propiciar una vivencia más libre. Varios ejemplos mostraban dis-

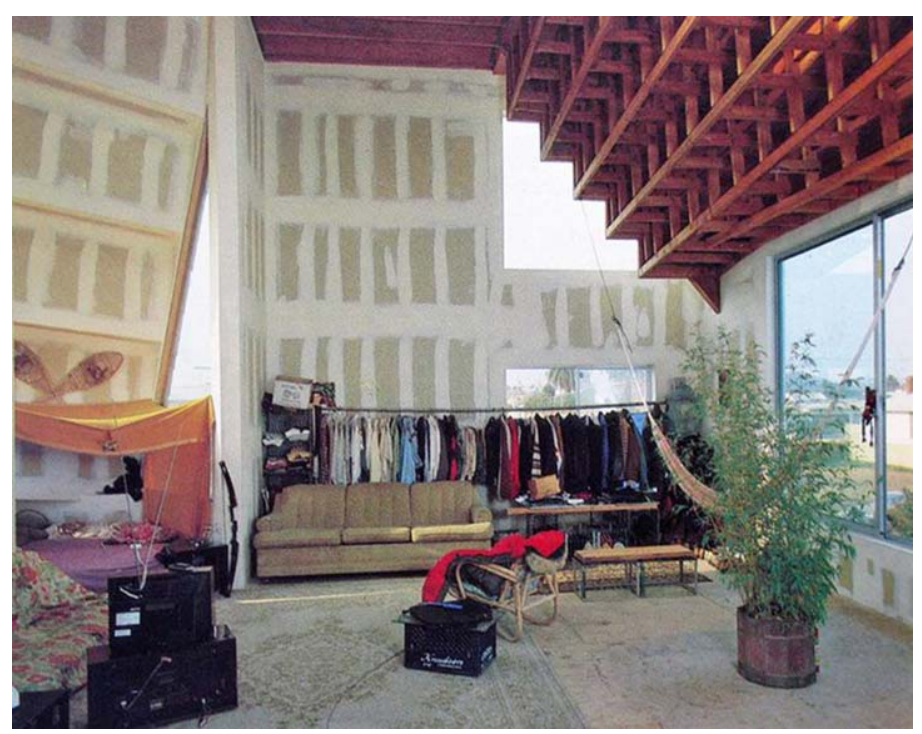

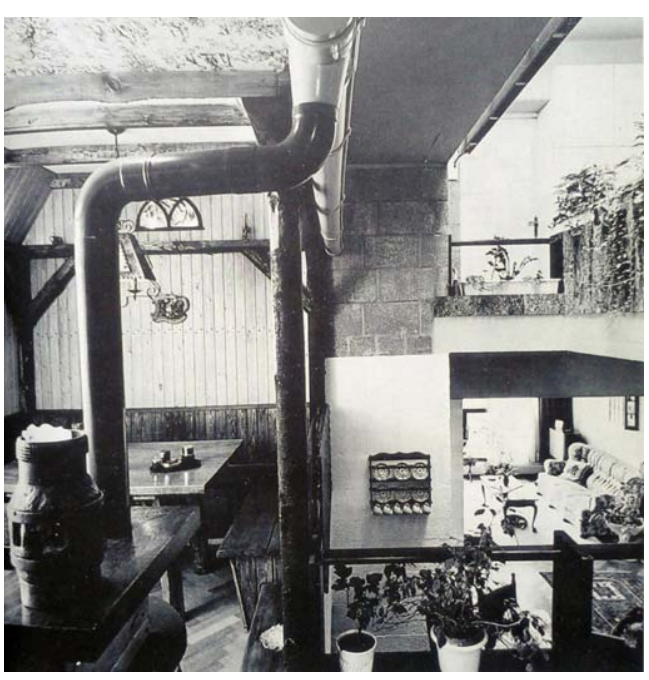

tintas formas de proyectar en base a estos planteamientos: por ejemplo, en algunos casos se recurria al lenguaje de los antiguos graneros americanos, en otros casos se dejaban conscientemente las viviendas 'inacabadas', como en las casas Diagoon de Herman Hertzberger en Delft (figura 17) para promover la finalización de las mismas en un acto de apropiación comunitario, con planteamientos de vida en comuna. Lo mismo ocurría en las viviendasestudio para artistas diseñadas en 1981 por Frank Gehry en Venice (figura 18). En otros casos se recreaban espacios con aspecto industrial, como en las viviendas sociales Nemausus de Jean Nouvel en Nîmes -1987-. En todos ellos, las características espaciales propiciaban la ocupación del entorno a través de la apropiación, como algo inherente a su vivencia.

\section{El objeto como mecanismo de transfor- mación espacial}

Vivencia, experiencia y percepción eran factores que también contribuían a definir aspectos propios del hábitat contemporáneo cuyo sujeto, sumergido en la sociedad de consumo, y mayormente hedonista, empezaba a reclamar lugares donde la experiencia de habitar fuera algo nuevo y excitante. En los años sesenta algunos arquitectos ligados a corrientes fenomenológicas, influidos por las ideas de filósofos como Merlau-Ponty o Bachelard partiendo de consideraciones subjetivas como la conciencia o la experiencia, pensaban que era posible modificar la percepción del espacio arquitectónico utilizando el objeto como mecanismo de transformación espacial. En aquellos casos, los sistemas utilizados podian ir unidos a planteamientos basados en la psicología de la percepción de configuraciones -gestalts- , al uso de la técnica con fines ilusionistas o a la aplicación de nuevos lenguajes, como el diseño 


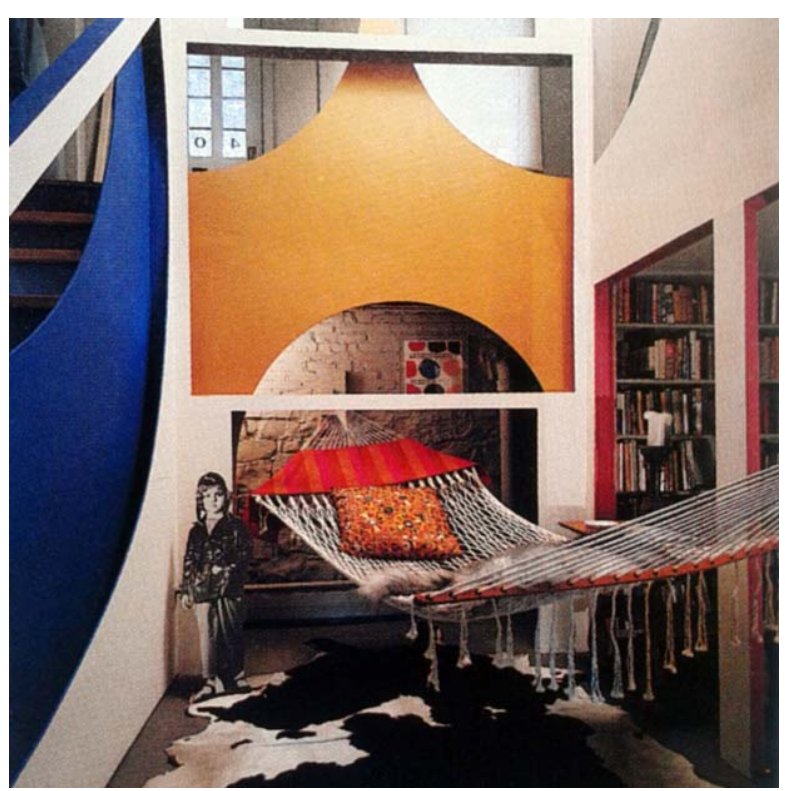

Figura 19

Casa Moore en New Haven. Vista interior de uno de los espacios que generaban los volúmenes verticales insertados, donde se aprecia los efectos de la superposición de capas, la mezcla de objetos descontextualizados y el uso de iluminación intencional (Moore et al. 1978: 306).

Figura 20. Casa Jay Wlock, New Haven. William Groover, 1968. Para aumentar la altura de la habitación, se diseñó una banda roja que se arremolinaba en el techo y continuaba recorriendo la pared. Ref. web 12. psicodélico, que habian surgido en aquellos años. ticut, recogía casi todos esos aspectos. Se trataba de una reforma, realizada por MLTW en 1967, que reconvirtió espacialmente una casa de finales del XIX utilizando una serie de mecanismos que modificaban la percepción de la misma. Los efectos ilusionistas que se generaron para aumentar la sensación de espacio estaban muy ligados a las leyes perceptivas de la buena forma, o de cierre -gestalt-. La interposición de objetos inacabados inducía a completarlos y a aumentar el tamaño de los ámbitos. La superposición de capas, de materiales livianos, de diferentes colores, la multiplicidad de cortes y huecos, y un sistema de pasos y recorridos proyectados con el fin de procurar una gran cantidad de visuales y perspectivas, caracterizaban el interior de la casa. El uso de técnicas de camuflaje, trompe l'oeil, anamorfismos, recursos de arte óptico - recordemos que
La casa Moore en New Haven, Connec-

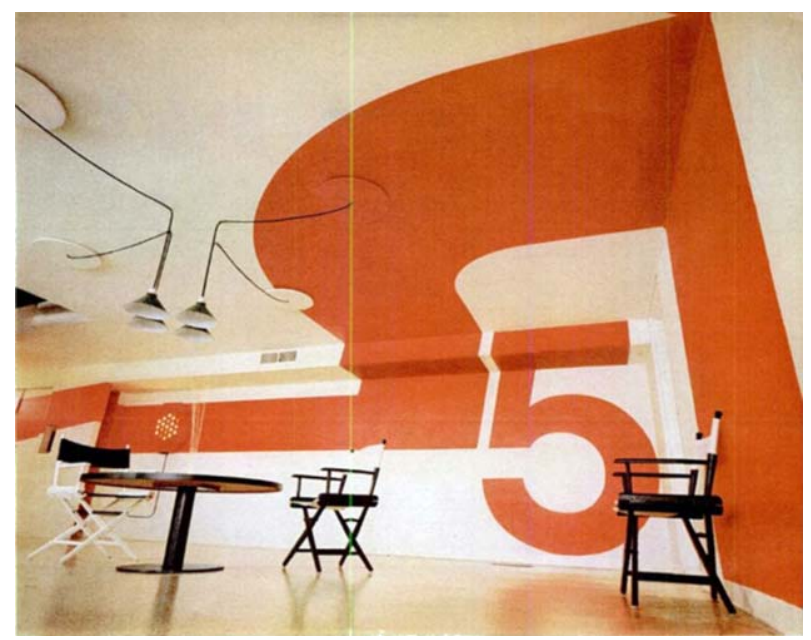

en 1965 el MoMA de Nueva York había celebrado una exposición de arte óptico llamada The Responsive Eye, y que habia tenido gran calado internacional- , generaban ambigüedad y desconcierto, algo que además iba acompañado con una iluminación intencional y con la incorporación de objetos de todo tipo, desde lo más clásico a lo más kistch, pasando por luces de neón y elementos propios de un centro comercial. Todo ello iba en pos de un espacio configurado de tal manera que sus efectos fueran alienantes.

En 1967, la revista Progressive Architecture publicaba un número al que tituló "Supergraphics". Todo empezó en 1965 cuando el grupo de arquitectos MLTW, estaba realizando el proyecto para los vestuarios del Sea Ranch Athletic Club y un problema de presupuesto los obligó a reducir su superficie, por lo que decidieron aumentar la percepción de los interiores dibujando gráficos a gran escala en todos los paramentos. Tuvo mucha aceptación, e incluso dicha publicación llegaba a denominarlo como una nueva forma de experimentación espacial. Un año después, la revista Life Magazine, editaba otro número en el que hacía especial hincapié en el uso del supergráfico en el interior doméstico. A pesar de que los supergráficos no eran objetos, sí tenían vocación de tridimensionalidad, y en su relación figurafondo generaban efectos espaciales similares a muchos objetos. Los juegos formales y de escala, incorporando elementos que demostraban que el uso del color ya se había liberado de los convencionalismos y de las normas del 'buen gusto'; a través de relaciones de fusión y contraste, de figura $\mathrm{y}$ fondo, o completando visualmente figuras inacabadas, conseguian modificar, o al menos perturbar, la percepción general del espacio, como se producían en la casa Jay Wlock en New Haven.

\section{La fusión: casa y objeto}

A veces, las relaciones topológicas de interpenetración que se generaban por la proliferación de objetos que inundaban los espacios producian un fenómeno de auténtica fusión entre la casa y el objeto. El concepto de 'aditamento' establecido por Moore en 1974, como necesario para crear vínculos afectivos con el espacio a través de los objetos personales, llevaba a la consideración de que esa complicidad, ya adquirida, entre las cosas y el entorno doméstico, propiciaba este efecto. (Moore, Allen y Lyndon 1999)

Los proyectos contemporáneos más significativos en este aspecto son la casa de los 
Figura 21.

Moore/Andersson Texas.

Moore/Andersson Architects. 1985. Vista del interior de la sala principal. Ref. web 13. Compound. Austin,

Eames en Santa Mónica -1949- y, posteriormente, varias de las casas de Charles Moore realizadas en los sesenta y setenta. Sin embargo, la última que realizó para sí mismo en Austin, Texas -1985- era uno de los ejemplos para ilustrar este efecto: grandes cantidades de objetos se acababan mezclando en un complejo sistema de capas superpuestas, y donde todo se fundía convirtiéndose en una gruesa piel. En este supuesto caos, finalmente todo se configuraba a lo largo de una estantería corrida con forma de elipse, la cual recorria el edificio y organizaba todo el espacio a su paso.

El desarrollo de aquella estantería además estaba pautado según la posición de unos talismanes -diseñados por Schinkel- y que el arquitecto había enmarcado en un sistema de pilastras que pautaban el recorrido y que convivian con todo tipo de colecciones y artefactos dispares.

\section{Objetos y recorrido}

La disposición de objetos en puntos estratégicos a lo largo la casa provocaba que, a modo de focos o hitos, los elementos fueran generando puntos de atención e incitaran al movimiento. De la percepción y la experiencia surgía otra manera de concebir la casa, entendida como un campo de exploración gracias a la creación de recorridos, a la invitación a descubrir a través de su vivencia, a la cual varios autores hacian alusión. Norberg-Schulz (2005: 65) hablaba de la idea de 'lugar' en arquitectura como otra forma de interpretación de la planta libre que se venía produciendo desde la segunda mitad del siglo XX. El enfoque era fenomenológico y su propósito era proporcionar lugares donde la vida pudiera 'tener lugar'. Para él un lugar era

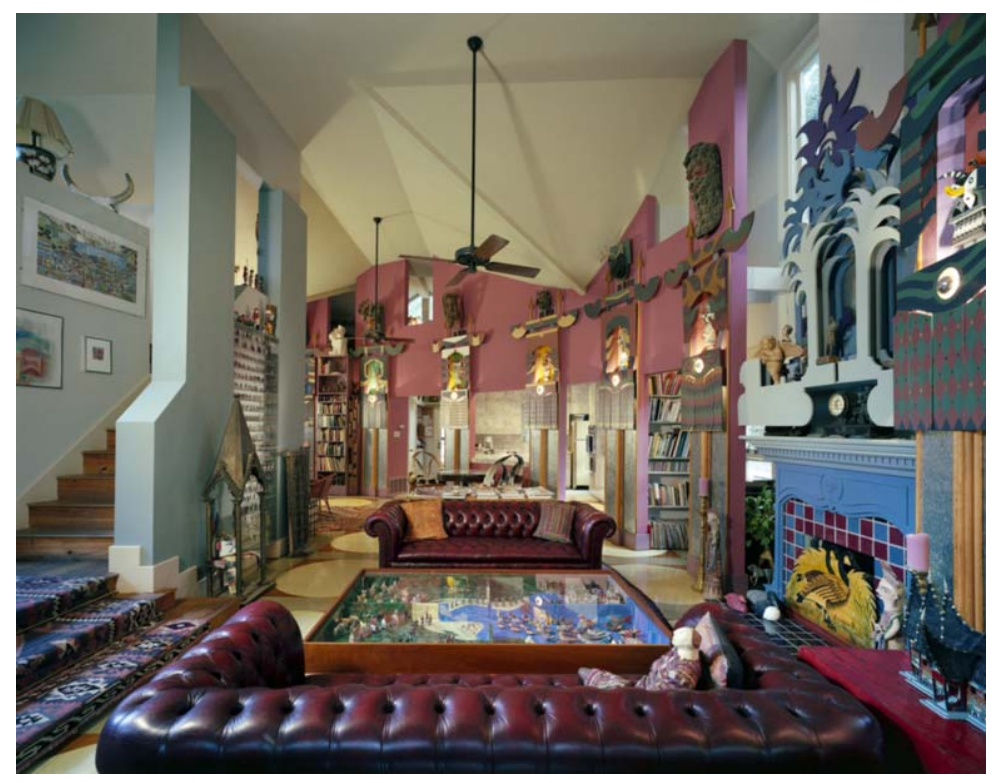

un entorno concreto que poseía orden y carácter, e iba implícito a la propia esencia de habitar. No tenía sentido hablar de la vida por un lado y del lugar por otro. El espacio doméstico podía entenderse desde las relaciones de sucesión de objetos, que provocaban movimientos o visuales, y que permitian tener un conocimiento del lugar a través de dicha práctica. Esta manera de concebir la casa partía de dos principios fundamentales, como base del proyecto: el concepto de 'lugar' en arquitectura y la consideración del movimiento del cuerpo en un espacio topológico.

Según Charles Jencks (1980: 126) la idea de lugar dentro de la casa podía equiparse a un campo de exploración, que se configuraba por los recorridos generados a través de un sistema de focos o puntos de atención distribuidos por toda la casa. Buscando ubicaciones estratégicas que despertaran la curiosidad, iban provocando el movimiento de los usuarios promovidos por la presencia de distintos objetos. Cada imagen que aparecía por el camino se convertía en un mero pretexto para realizar más descubrimientos.

Un ejemplo era la casa Blackburn de Peter Wilson -1986- donde, en este caso, los recorridos se producian por una sucesión de diferentes piezas de arte y de muebles de diseño, donde cada elemento se iba añadiendo a un fondo blanco. Un gran hueco acristalado, con un pilar de acero pintado de azul, a modo de tótem, marcaba el punto de partida del recorrido. La planta baja era una oficina, las otras dos plantas superiores eran un apartamento que albergaba una colección de arte y objetos de diseño contemporáneo. Todas las piezas habian sido encargadas ex profeso para la propia casa: una silla de Scott Burton, una liebre de Barry Flanagan, un retrato de Andy Warhol, una mesa de Bruce Mclean, un sofá de Jasper Morrison, otra mesa de Ron Arad, etc. y habian sido colocadas estratégicamente para generar un camino de abajo a arriba. El visitante sólo terminaba de entender la casa cuando llegaba al último piso donde, en medio del salón-comedor, un banco de madera flotaba sobre el gran ventanal y permitía sentarse para contemplar desde arriba todo el recorrido pautado por las piezas de arte.

Cada pieza hablaba por sí misma, pero las relaciones y conexiones que se producian por la disposición de las obras, prevalecían en aquel ritual, que era lo que realmente daba sentido a la casa.

Baudrillard (1967: 17) decía que sin relación no había espacio. Y ese es quizá el 


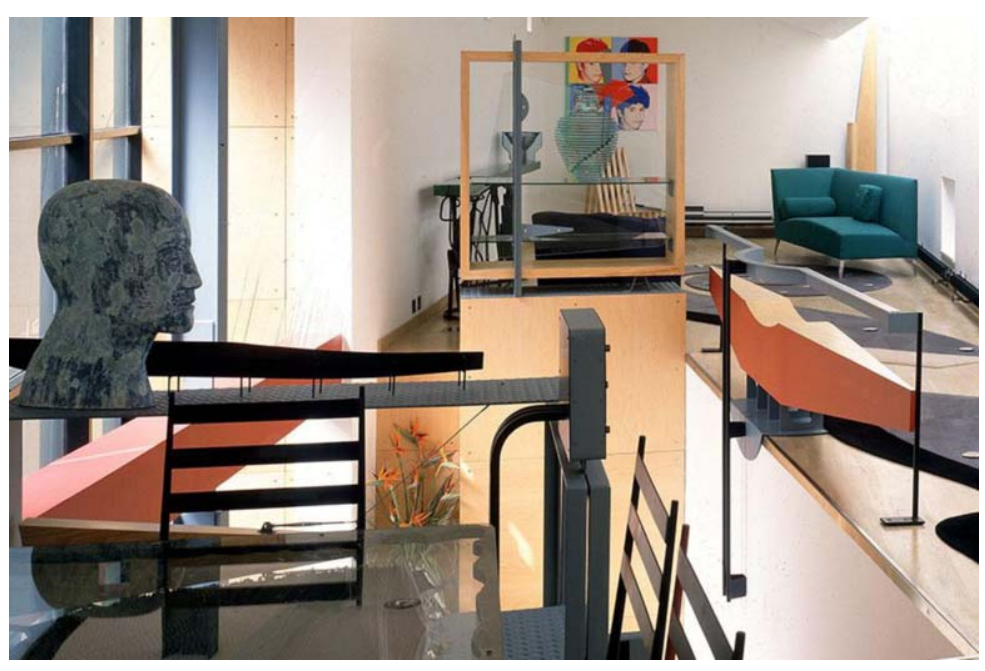

Figura 22. Casa Blackburn, Hampstead, Londres. Peter Wilson. 1986. Vista de los distintos objetos, que se convierten en puntos de referencia y organizan el recorrido. Ref. web 14.

denominador común de esta sinergia entre los diversos entornos y las diferentes maneras en que los objetos se constituian como agentes configuradores. La mayor libertad en el espacio, por sus propias to como elemento comunicador eran la base de las posibilidades que se ofrecian para establecer un discurso, conforme a características, y la nueva faceta del objeuna amplia combinatoria de distribución de objetos cotidianos y dentro de una nueva estructura: el espacio doméstico contemporáneo.

\section{Notas}

1. Entre los principales estudios sobre el objeto destacan los de Barthes (2009), Baudrillard (1969) y Moles (1975).

2. Glass House: 1949, Nuevo Canaan, Connecticut. Casa Farnsworth: 1951, Plano, Illinois.

3. Casa Eames, conocida como Case Study House 8: 1949, Santa Monica, California.

4. En su artículo "A home is not a house" (Banham 1965).

5. La colocación de objetos, como tratamiento del espacio, se convertía en parte del discurso de ambiente. (Baudrillard 1969: 31).

6. Moles (1975: 111), dentro de lo que llamaba las 'leyes sintácticas de acoplamiento', enunciaba la ley de irradiación del objeto, a través de la cual hace referencia al fenómeno psicológico de que todo objeto irradiaba a su alrededor, de que dominaba psicológicamente un sector de su entorno, estableciendo a su alrededor un volumen propio o esfera de influencia. En este proceso el objeto exigía un dominio autónomo, vacío de otros objetos de su misma dimensión.

7. (Moles, 1975: 111) La ley de accesibilidad establecia que para que un objeto, un mueble o una posesión cualquiera fuera utilizable, era preciso que resultase accesible sin esfuerzo; esto determinaba conscientemente la disposición topológica de una habitación.

8. Roto-living contaba con reloj, televisión, equipo de música y sistema de iluminación. Con un giro surgía una mesa de comedor o una coffee-table con bar incluido. Cabriolet-Bed, con la capota cerrada ofrecía privacidad, con la capota abierta se convertía en zona de relax y disfrute musical.

9. Los talismanes habian sido diseñados por Schinkel para la escenografia de La flauta mágica de Mozart en 1816, y fueron adquiridos por Moore.

\section{Bibliografia}

Allen, Gerald (ed.). 1980. Charles Moore, by Gerald Allen. Nueva York: Whitney Library of Design.

Banham, Reyner. 1965. A home is not a house. Art in America, 2: 70-79.

BARTHEs, Roland. 2009. Semántica del objeto. En: La aventura semiológica. Barcelona: Paidós. 321-336.

BAUdRILlARD, Jean. 1969. El Sistema de los Objetos. México: Siglo XXI.

Friedman, Mildred (ed.). 2009. Frank Gehry: The Houses. Nueva York: Rizzoli.

GEHRY, Frank O. 1988. La arquitectura de Frank Gehry. Barcelona: Gustavo Gili.

HeRTZBERGer, Herman. 1991. Herman Hertzberger, 1959-1990. Tokio: A+U Publishing.

JencKs, Charles. 1980. El lenguaje de la Arquitectura Posmoderna. Barcelona: Gustavo Gili.

Johnson, Eugene J. (ed.). 1986. Charles Moore. Buildings and Projects 1949-1986. Nueva York: Rizzoli.

KRIES, Mateo y von Vegesack, Alexander (ed.). 2005. Joe Colombo. Inventing the future. Weil am Rheim: Vitra Design Museum.

Moles, Abraham A. 1975. Teoria de los Objetos. Barcelona: Gustavo Gili.

Moore, Charles W., et al. 1978. The Work of Charles W. Moore. $A+U$ Architecture and Urbanism, extra-mayo.

Moore, Charles W., Allen, Gerald y Lyndon, Donlyn. 1999. La casa: forma y diseño. Barcelona: Gustavo Gili S.A.

NoRBERG-Schulz, Christian. 1998. Intenciones en arquitectura. Barcelona: Gustavo Gili.

NorberG-Schulz, Christian. 2005. Los Principios de la Arquitectura Moderna. Barcelona: Reverté.

Sмith, C. Ray. 1967. Bathhouse graphics. Progressive Architecture, marzo: 156-161.

Vidotto, Marco (ed.) 1997. Alison + Peter Smithson. Barcelona: Gustavo Gili.

\section{Referencias de imágenes}

Ref. web 1:

http:/ / eamesfoundation.org/visit/interiortours / (visitado 25 jun.2017)

Ref. web 2: http://oma.eu/projects/casa-palestra (visitado 25 jun.2017)

Ref. web 3:

https://www.curbed.com/2016/9/16/1294427 4/ (visitado 18 abr.2017)

Ref. web 4:

http://www.klatmagazine.com/en/architectureen/storie-dinterni/51345 (visitado 25 jun.2017) Ref. web 5:

http:/ / www.hiddenarchitecture.net/2017/01/vi lla-van-wassenhove.html (visitado 25 jun.2017) Ref. web 6: http://bijoukaleidoscope.com/ahouse-from-a-dream/ (visitado 25 jun.2017) Ref. web 7: http://www.domusweb.it/en/fromthe-archive/2011/09/01/joe-colombo-s-ownshow-home.html (visitado 20 abr.2017) Ref. web 8: http://socks-

studio.com/2015/03/22/the-house-sees-itselfreflected-in-the-office-abalos-herreros-housingcity-barcelona-1988/ (visitado 20 abr.2017) Ref. web 9: http://jaumeprat.com/la-vivienda- 
difusa/ (visitado 18 abr.2017)

Ref. web 10: http://www.stevenholl.com/pro-

jects/fukuoka-housing (visitado 18 abr.2017)

Ref. web 11: https://warholfactoryinart.wordpress.com/2016/03/16/wharol-sa-fabrique-asuperstars-un-esprit-federateur/ (visitado 18 abr.2017)

Ref. web 12:

http://sighswhispers.blogspot.com.es/2012/04

/at-home-its-supergraphics-1968.html (visita-

do 21 abr.2017)

Ref. web 13:

http://www.timothyhursley.com/architectureretrospective/ (visitado 18 abr.2017)

Ref. web 14 :

http://www.chassaystudio.com/the_home/blac kburn_house (visitado 15 abr.2017) 